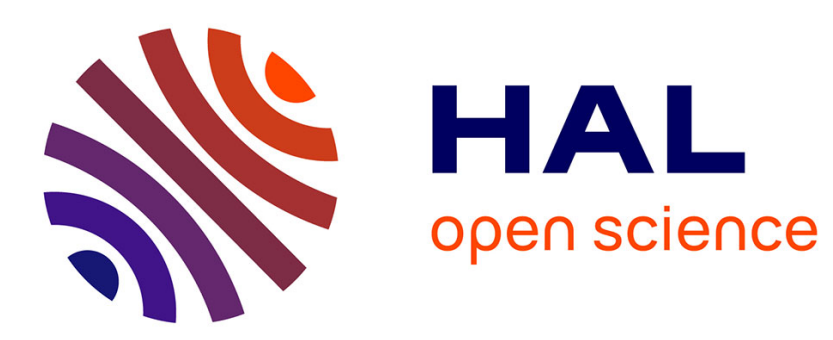

\title{
Tribo-electrochemical impedance: A new technique for mechanistic study in tribocorrosion
}

\author{
Michel Keddam, Pierre Ponthiaux, Vincent Vivier
}

\section{To cite this version:}

Michel Keddam, Pierre Ponthiaux, Vincent Vivier. Tribo-electrochemical impedance: A new technique for mechanistic study in tribocorrosion. Electrochimica Acta, 2014, 124, pp.3-8. 10.1016/j.electacta.2013.08.186 . hal-01015230

\section{HAL Id: hal-01015230 \\ https://hal.sorbonne-universite.fr/hal-01015230}

Submitted on 2 Sep 2014

HAL is a multi-disciplinary open access archive for the deposit and dissemination of scientific research documents, whether they are published or not. The documents may come from teaching and research institutions in France or abroad, or from public or private research centers.
L'archive ouverte pluridisciplinaire HAL, est destinée au dépôt et à la diffusion de documents scientifiques de niveau recherche, publiés ou non, émanant des établissements d'enseignement et de recherche français ou étrangers, des laboratoires publics ou privés. 


\title{
Tribo-electrochemical impedance.
}

\section{A new technique for mechanistic study in tribocorrosion.}

\author{
Michel KEDDAM ${ }^{1, *}$, Pierre PONTHIAUX ${ }^{2}$, Vincent VIVIER ${ }^{1}$ \\ ${ }^{1}$ LISE-Laboratoire Interfaces et Systèmes Electrochimiques, Université P. et M. Curie, \\ 4, place Jussieu, 75252 Paris Cedex 05, France. \\ *Corresponding author: michel.keddam@upmc.fr \\ ${ }^{2}$ Laboratoire LGPM, Ecole Centrale, Rue des Vignes, 92290, Châtenay-Malabry, \\ France.
}

\section{Abstract}

On the basis of a classical model of triboelectrochemistry, a new approach is proposed based on an impedance ratio of a mechanical perturbation and of an electrochemical response. Theoretical derivation, experimental setup and application to a passive stainless steel in a borate solution are presented. Transient characteristics yielded by the technique, associated to a permanent tribological regime, are found to obey a two-time-constant law. They are discussed and compared to the global repassivation transients of the material after switching off the abrasive friction.

\section{Introduction}

Tribo-corrosion is defined as the degradation of a material under the effect of both mechanical and reactive damages. It is established that these two modes of attack are not simply additive and that in most cases intricate cross-effects are at work. Therefore the main goal of investigations carried out in this domain is to understand the mechanisms involved in this so-called synergism and to establish 
techniques for forecasting the behavior of a material exposed to a risk of tribocorrosion.

Incorporating a mechanical disturbance of the interface within an electrochemical environment of the interface has led to the concept of tribo-electrochemistry. However, the extension of traditional electrochemical techniques developed for corrosion free of mechanical contribution is facing both experimental and conceptual problems. Their theoretical background, experimental applicability and limitations have been reviewed in a recent publication [1]. Open-circuit potential, current-voltage curves and electrochemical impedance [2] have been used under tribological conditions compatible with a permanent regime, e.g. a constant current at a given potential. Valuable results were reported but no quantitative treatments are available. Electrochemical responses to transient abrasion regimes have been also investigated and tentatively interpreted on the basis of repassivation models depicting the growth of the passive film after being removed by the rubbing body [3]. This paper presents a new approach exploring the kinetics of the film healing by a sine-wave modulation of the velocity of rotation of a Pin-On-Disc tribometer. A complex transfer function is hence defined depicting, in the frequency domain, the repassivation transient behind the sliding body on the disc.

The background of the technique, its experimental aspects and first results obtained in the passive range of a stainless steel are presented.

\section{Background}

In contrast with traditional physicochemical parameters, the interaction between a metal and an antagonistic abrading body cannot be directly incorporated in the framework of electrode kinetics. The effect is definitely invasive and for an electrochemist the result is a nightmare: the total destruction of the interface. Referring to classical interfacial electrochemistry, the 
only available examples of abrading the interface and focussing on what happens immediately afterwards are relative to studies of the double layer capacitance. [4], [5], [6]. The same concept of fresh surface created by mechanical surface removal was thoroughly exploited in works aimed at understanding the mechanism of various type of corrosion such as abrasion corrosion, SCC, laser and ultrasonic impacts.... All are supposed to be in some way controlled by the competition between the local mechanical breakdown of a protective film and the reconstitution of the later by a healing process. The first explicit expression of the current generated by a rubbing body has been given in the form of an integral in [7]. It remains the background of the quantitative applications of electrochemical techniques to tribocorrosion. In Fig. 1 a formally general case is considered in which rubbing removes all the surface layer and further ploughs deeper into the underlying metal.

\section{Insert Fig 1 here.}

It is noteworthy that the quantity $|v| .\left|\vec{f}_{t}\right|$ is the mechanical power $\mathrm{W}_{\mathrm{m}}$ injected in the system. It is consumed in irreversible processes of heat generation, plastic deformation, breakdown of the metallic bonds... and reversible ones like elastic deformation. The double layer charging current $\mathrm{j}_{\mathrm{dl}}$ is generally not mentioned in tribocorrosion and can be actually neglected, [3]. The surface charge, around $1 \mathrm{mC} . \mathrm{cm}^{-2}$ being orders of magnitude smaller than that consumed in the electrochemical reactions associated to passivation, typically a fraction of C.cm ${ }^{-2}$ and a fortiori to anodic dissolution during the transient regime. A more detailed discussion of this model can be found in [1].

\subsection{General mathematical developments}

If the sample is supposed to be at a constant potential, the current measured at any distance $\mathrm{x}$ from the starting point is given by integrating the local current density $\mathrm{j}(\mathrm{x})$ over the width $\mathrm{w}$ 
of the track and its length, with the origin of the successive positions being attached to the abrasive pin and the $\mathrm{x}$ axis oriented positively to the left:

$$
I(x)=w \int_{0}^{x} j(x) d x
$$

In the case of a constant velocity, $\mathrm{v}$, changing the variable from $\mathrm{x}$ to $\mathrm{t}$ gives:

$$
I(t)=w \cdot v \int_{0}^{t} j(t) d t
$$

where $v$ is the modulus of $\vec{v}$ defined in Fig. 1 . If the integral is convergent, $I(t)$ reaches a limiting value $I_{\infty}$ given by Eq.2 for $t>$ characteristic-time of the surface recovery.

$$
\mathrm{I}_{\infty}=\mathrm{W} . \mathrm{V} \cdot \mathrm{Q}
$$

where $\mathrm{Q}$ is the total surface density of charge, in $\mathrm{C}$ by unit area, consumed in the whole transient.

From a kinetics viewpoint, in Eq.(3) v plays a role identical to a rate constant in the expression of an electrochemical current. However it must be emphasized that $\mathrm{I}(\mathrm{t})$ does not give access directly to $\mathrm{j}(\mathrm{t})$; Eq (2) has been exploited in various ways for interpreting many tribocorrosion measurements in transient regimes of sliding velocity and current. The present work is based on a generalized form of Eq (2) valid for any case where $\mathrm{v}$ is no longer independent of time $t$. At any time $t$, the contribution to the total current $I(t)$ of a small section of the track created at the time $(t-\tau)$ when the velocity was $v(t-\tau)$ is given by $j(\tau) \cdot v(t-\tau)$.

\section{Insert Fig 2 here.}

Hence the current $I(t)$ is expressed as the convolution product of the functions $j$ and $v$ :

$$
I(t)=w \int_{0}^{t} j(\tau) \cdot v(t-\tau) d \tau
$$

\subsection{The Tribo-Electrochemical Impedance}


Now if we consider the case of a small amplitude sine wave modulation of $v(t)$ about a constant mean value $\mathrm{v}_{\mathrm{o}}, \mathrm{v}(\mathrm{t})=\mathrm{v}_{\mathrm{o}}+|\Delta \mathrm{v}| \mathrm{e}^{\mathrm{j} \omega \mathrm{t}}, \mathrm{Eq}(4)$ can be rewritten as:

$$
I(t)=w_{o} \int_{0}^{t} j(\tau) d t+w \int_{0}^{t} j(\tau)|\Delta v| e^{j \omega(t-\tau)} d \tau
$$

In $\operatorname{Eq}(5)$ the first term is the response to the velocity $v_{0}$ given by $\mathrm{Eq}(2)$ while the second one is the ac response $\Delta \mathrm{I}$ of the current induced by the modulated component of the velocity $|\Delta v| \mathrm{e}^{\mathrm{j} \omega \mathrm{t}}$. Therefore a complex transfer function, $\mathrm{TEI}_{\mathrm{E}}$ (Tribo-Electrochemical Impedance at constant potential) can be defined relating the frequency response of the current to the velocity modulation:

$$
\mathrm{TEI}_{\mathrm{E}}=\frac{\Delta \mathrm{I}}{\Delta \mathrm{v}}=\mathrm{w} \int_{0}^{\mathrm{T}} \mathrm{j}(\tau) \cdot \mathrm{e}^{-\mathrm{j} \omega \tau} \mathrm{d} \tau
$$

Only this derivation has a physical meaning only if a constant mean current can be reached given by $\mathrm{Eq}(2)$. A linear abrasion trajectory should in practice have an "infinite" length for $\mathrm{Eq}(3)$ to be valid. This problem has been overcome by the design of rotating tribometers of the Pin-On-Disc or Ball-On-Disc type where the abrading body moves on a circular trajectory. According to the foregoing model, after one period of rotation, $\mathrm{T}$, the current reaches a constant value:

$$
I(T)=w \cdot v \int_{0}^{T} j(t) d t
$$

The linear velocity $\mathrm{v}$ can be converted into an angular one, e.g. $\mathrm{RPM}: \mathrm{v}=2 \pi \mathrm{r} \Omega_{\mathrm{RPM}} / 60$. It must be emphasized that this constant value of the current must not be mistaken with a steady-state as in traditional electrochemistry. In fact any point of the abraded surface is in a dynamic regime given by $\mathrm{j}(\mathrm{t})$, the constant current results only from the travelling transient current attached to the abrading body. This is why modeling the traditional EIS response of this "pseudo-steady-state system" could be a delicate but worthy task.

The final form of $\operatorname{Eq}(7)$ becomes: 


$$
\mathrm{TEI}_{\mathrm{E}}=\frac{\Delta \mathrm{I}}{\Delta \mathrm{v}}=\mathrm{w} \int_{0}^{\mathrm{T}} \mathrm{j}(\tau) \cdot \mathrm{e}^{-\mathrm{j} \omega \tau} \mathrm{d} \tau
$$

The $\mathrm{TEI}_{\mathrm{E}}$ expressed by $\mathrm{Eq}(8)$ is a one-sided $(\mathrm{t}>0)$ Fourier transform of $\mathrm{j}(\mathrm{t})$ in a time-window of length T. As shown below, even though $\mathrm{j}(\mathrm{t})$ is not readily extracted from the $\mathrm{TEI}_{\mathrm{E}}$, pertinent information on $\mathrm{j}(\mathrm{t})$ can be gained by a simulation approach. It must be emphasized that $\mathrm{Eq}(8)$ offers a totally original way of investigating the electrochemical response of a surface about a mean steady-state tribo-corrosion regime whilst available techniques are confined to large transients between no abrasion and full abrasion conditions.

\section{Experimental}

The equipment shown in Fig3 depicts a Pin-On-Disc tribo-electrochemical experiment, either in a fix disc-rotating pin configuration or in the opposite one, in this work a fix disc setup was used. The electrochemical control of the working electrode submitted to abrasion is classically performed by a Solartron 1286 potentiostat. The tribological conditions, normal force $\mathrm{f}_{\mathrm{n}}$ (see figure 1) and pin velocity are controlled by a P-O-D tribometer Falex and the associated RSAI software. The current flowing through the cell and the velocity of the pin are numerically stored in two channels of a PowerLab/8SP -ADInstruments. The working electrode is a disc of $25 \mathrm{~mm}$ in diameter and the circular abraded ring as a radius of $5 \mathrm{~mm}$. The abrading body is a zirconia rod, $7 \mathrm{~mm}$ in diameter, terminated by a cap part of a spherical surface $100 \mathrm{~mm}$ of curvature diameter. The surface of the working electrode is machined and mechanically polished after each set of measurements at a given rotation speed. A critical point is to achieve as far as possible an even surface flat and normal to the rotation axis.

\section{Insert Fig 3 somewhere here.}

\section{Results}

\subsection{Validation and data processing}


In a first step, experimental data were validated in several ways. TEI implying an additional quantity $\Omega$ with respect to the usual pair I-E must be tested against the general relationship holding between the 3 pairs of command inputs:

$$
\left(\frac{\Delta \mathrm{E}}{\Delta \mathrm{I}}\right)_{\Omega}=\mathrm{Z}=-\left(\frac{\Delta \mathrm{E}}{\Delta \Omega}\right)_{\mathrm{I}} /\left(\frac{\Delta \mathrm{I}}{\Delta \Omega}\right)_{\mathrm{E}}=-\frac{\mathrm{TEI}_{\mathrm{I}}}{\mathrm{TEI}_{\mathrm{E}}}
$$

Where $\mathrm{Z}$ is the traditional electrochemical impedance at the mean value of: $\Omega=\Omega_{0}, \mathrm{TEI}_{\mathrm{I}}$ and $\mathrm{TEI}_{\mathrm{E}}$ are the Tribo-Electrochemical-Impedances at constant current and constant potential respectively. Eq (9) initially introduced with the Electro-Hydrodynamic-Impedance was recently generalized in [8]. In order to apply Eq (9) the Open-Circuit condition was selected where the interface can be maintained either at constant current or at constant potential, a requirement not fulfilled in the passive range where the rest of the study was performed.

\section{Insert Fig 4 and 5 here.}

The comparison of Fig. 4 et 5 indicates a fair agreement between the measured and calculated Nyquist plots in terms of size and frequency location even though above $1 \mathrm{~Hz}$ the poor accuracy of the TEI's data affected the reliability of the comparison.

Two important validity conditions of any impedance were also tested: the acceptable sinewave shape of the ac response and the low level of harmonics meaning a correct linearity.

\section{Insert Fig 6 and 7 here.}

Fig 6 shows a sample of a current response after a low-pass filtering $(\mathrm{f}<0.1 \mathrm{~Hz})$ with the Sigview 2.5.1 (SigviewLab) which was used for all the signal processing including filtering and computation of the $\mathrm{TEI}_{\mathrm{E}}$ by correlation algorithms of $\Delta \mathrm{I}(\mathrm{t})$ with $\Delta \Omega(\mathrm{t})$. The corresponding spectrum of Fig 7 shows the low level of the second and third harmonics even at the large relative modulation of 0.3 .

\subsection{Analysis of the repassivation transient in the passive range}


The $\Delta \mathrm{I}$ and $\Delta \Omega$ data have been collected between $0.01 \mathrm{~Hz}$ and $10 \mathrm{~Hz}$ at a potential in the full passive domain of the AISI 316 L S.S. in the same conditions as for Fig. 6 and for three mean rotation speeds: 8, 20 and 50RPM of the abrading pin. After processing frequency by frequency, the complex $\mathrm{TEI}_{\mathrm{E}}$ was plotted in the Nyquist plane.

\section{Insert Fig 8 here}

Fig 8 displays the plot corresponding to 20 RPM, its lies in the third quadrant of the complex plane (like for a capacitive impedance plot the imaginary axis is reversed). The low frequency limit, positive, is in satisfactory agreement with the slope of the steady-state $\mathrm{I}(\Omega)$ curve and the loop is consistent with a time-delayed increase of the current following an increment of abrasion velocity. The shape, clearly depressed, is not compatible with an exponential $j(t)$ which would generate a semi-circle for the integral in $\mathrm{Eq}(8)$ extending to infinity as shown by $\operatorname{Eq}(10)$.

$$
\mathrm{TEI}_{\mathrm{E}}=\frac{\Delta \mathrm{I}}{\Delta \mathrm{v}}=\mathrm{w} \int_{0}^{\infty} \mathrm{e}^{-\frac{\tau}{\tau_{1}}} \cdot \mathrm{e}^{-\mathrm{j} \omega \tau} \mathrm{d} \tau=\mathrm{w} \frac{\tau_{1}}{1+\mathrm{j} \omega \tau_{1}}
$$

The same features were obtained at the rotation speeds 8 and 50 RPM with a frequency dispersion that can be displayed clearly only in the Bode plot (log, modulus, log, frequency). These Bode plots suggested rather than a quite formal exploitation in terms of a CPE, to propose an interpretation by the sum of two exponentials $\lambda_{1} \mathrm{e}^{-\frac{\mathrm{t}}{\tau_{1}}}$ and $\lambda_{2} \mathrm{e}^{-\frac{\mathrm{t}}{\tau 2}}$. In order to account for the windowing effect in Eq (8), the experimental data were hence compared to the numerical values generated by $\operatorname{Eq}(8)$ with $\mathrm{j}(\tau)=\lambda_{1} \mathrm{e}^{-\frac{\tau}{\tau_{1}}}+\lambda_{2} \mathrm{e}^{-\frac{\tau}{\tau 2}}$ with the value of $\mathrm{T}$ corresponding to the actual $\Omega_{0}$; the Mathcad 15.0, (PTC) was used for that. The value of $w$ being dependent on the particular experiment considered, through the behaviour of the solidto-solid friction, the duration of the measurement... $\lambda_{1}$ and $\lambda_{2}$ will be expressed in the form of their products by w in A.m ${ }^{-1}$. They can be re-evaluated afterward by using the track width 
obtained from optical estimations on worn electrodes. Parameters values were estimated by a trial-and-error procedure based on the modulus and phase Bode plots.

\section{Insert Fig 9 here.}

Fig 9 shows the experimental data for three values of $\Omega_{\mathrm{o}}$ in the Bode modulus plane and the results of simulation with $\mathrm{Eq}(8)$ by using the values of parameters given in the Table 1 . A quite satisfactory match is observed considering the rather large scattering of the TEI points. The main source of error is the parasitic modulation of the current at the rotation frequency due to the lack of levelness of the electrode surface in spite of a careful machining.

\begin{tabular}{|l|l|l|l|l|l|l|l|l|}
\hline$\Omega_{0} ; \mathrm{RPM}$ & $\mathrm{w} \lambda_{1} ; \mathrm{A} . \mathrm{m}^{-1}$ & $\mathrm{w} \lambda_{2} ; \mathrm{A} . \mathrm{m}^{-1}$ & $\tau_{1 ;} \mathrm{s}$ & $\tau_{2}, \mathrm{~s}$ & $\lambda_{1} ; \mathrm{A} . \mathrm{m}^{-2}$ & $\lambda_{2} ; \mathrm{A} . \mathrm{m}^{-2}$ & $\tau_{1} \lambda_{1} ; \mathrm{C}^{-\mathrm{m}^{-2}}$ & $\tau_{2} \lambda_{2} ; \mathrm{C} . \mathrm{m}^{-2}$ \\
\hline 8 & 0.000078 & 0.000468 & 1.5 & 0.1 & 0.156 & 0.936 & 0.234 & 0.0936 \\
\hline 20 & 0.0000052 & 0.000156 & 3 & 0.3 & 0.0104 & 0.312 & 0.0312 & 0.094 \\
\hline 50 & 0.00000338 & 0.000195 & 2 & 0.2 & 0.00676 & 0.39 & 0.0135 & 0.078 \\
\hline
\end{tabular}

Table 1: values of the parameters, pre-exponential factors, time-constants and surface charges determined by a simulation procedure of the $\mathrm{TEI}_{\mathrm{E}}$ data for three rotation speeds of the abrading pin shown in Figs 8 and 9.

\subsection{Discussion}

It is clear that $\mathrm{j}(\mathrm{t})=\lambda_{1} \mathrm{e}^{-\frac{\mathrm{t}}{\tau_{1}}}+\lambda_{2} \mathrm{e}^{-\frac{\mathrm{t}}{\tau 2}}$ is dependent on $\Omega_{0}$, in contrast with the literature model at the origin of this work which is based on a same kernel transient. The time-constants $\tau_{1}$ and $\tau_{2}$ remained of the same order of magnitude and their ratio $\tau_{1} / \tau_{2}$ close to 10 . The amplitude $\lambda_{1}$ decreased as the rotation speed goes up whilst $\lambda_{2}$ is little dependent with no clear trend. The consideration of the density of charge $\tau_{i} \lambda_{i}$ involved under the two components of $j(t)$ brings about a more relevant insight since likely less sensitive to experimental dispersion. The results are given in the right hand side of the Table 1, in surface density of charge. A value of w close to $0.0005 \mathrm{~m}$ was estimated by surface examination giving respectively for 8,20 and 50 RPM 
the values of $\lambda_{1}$ and $\lambda_{2}$ reported in the Table 1 . The charge associated to the shorter timeconstant $\tau_{2}$ can be regarded as constant whilst the charge passed during the larger timeconstant $\tau_{1}$ increases with the rotation period. One can infer that the time-constants correspond to two different surface processes. The shorter would reflect a fast process independent of the overall electrochemical activity, linked to $\Omega_{\mathrm{o}}$, of the surface, the longer one to a slower relaxation strongly coupled to the average degree of recovery of the surface. This is clearly not included in the model initially considered in this work and must be the starting point of an original effort of modeling in the field.

Another problematic aspect is raised by the order of magnitude of the surface charges. If compared to the reference density of faradaic charge involved in the growth of a conventional passive film, they are far too small. The same remark would be easily formulated by comparing the steady-state current at any $\Omega_{\mathrm{o}}$ value to its value calculated by $\mathrm{Eq}(1)$. One possible explanation is a strong overestimation of the true active area. An effective contact area restricted by the surface roughness has been already pointed out on the same material [9]. The total damage width is also probably much larger than that really affected by the mechanical interaction with the pin at a given stage of the experiment. The final aspect would be due to both the superposition of a large number of rotations and of an active dissolution of the nearby metal sustained by ohmic drop $[10,11]$. Repassivation by galvanic coupling to the surrounding passive area, not detected in the measured current, well-known in the case of local depassivation experiments [12] must be also considered.

This mathematical form of $\mathrm{j}(\mathrm{t})$ provided by $\mathrm{TEI}_{\mathrm{E}}$ being not explicitly reported in the literature has prompted to perform independent characterization of the transient response. Current decays were recorded at the end of each $\mathrm{TEI}_{\mathrm{E}}$ sequence on steping to zero the rotation of the pin led, they led to the same conclusions. The current returned to its undisturbed passive value, an example is given in Fig10 with the best fit to a sum of two exponentials, 


\section{Insert Fig 10 here}

$\mathrm{I}=\mathrm{L}_{1} \cdot \mathrm{e}^{-\frac{\mathrm{t}}{\mathrm{T}_{1}}}+\mathrm{L}_{2} \cdot \mathrm{e}^{-\frac{\mathrm{t}}{\mathrm{T}_{2}}}$ by a Least Square Regression, performed in Kaleidagraph 4.03 (Synergy

Software). A similar behaviour was obtained for the three values of $\Omega_{0}$. The data are reported in Table 2.

\begin{tabular}{|l|l|l|l|l|l|l|}
\hline$\Omega_{0}$ & $\mathrm{~T}_{1} ; \mathrm{s}$ & $\mathrm{T}_{2} ; \mathrm{s}$ & $\mathrm{L}_{1} ; \mathrm{A} . \mathrm{m}^{-2}$ & $\mathrm{~L}_{2} ; \mathrm{A} . \mathrm{m}^{-2}$ & $\mathrm{~T}_{1} \cdot \mathrm{L}_{1} ; \mathrm{Cm}^{-2}$ & $\mathrm{~T}_{2} . \mathrm{L}_{2} ; \mathrm{Cm}^{-2}$ \\
\hline 8 RPM & 50 & 5 & 0.1 & 0.115 & 5 & 0.575 \\
\hline 20 RPM & 25 & 1.2 & 0.17 & 0.36 & 4.25 & 0.43 \\
\hline 50 RPM & 13.9 & 0.66 & 0.57 & 2.5 & 7.9 & 1.65 \\
\hline
\end{tabular}

Table 2 : values of the parameters, pre-exponential factors, time-constants and surface charges determined by a Least Square Fitting of the current transients after stopping the pin rotation for the three rotation speeds. The transient at 20 RPM is shown in Fig 10.

Unlike for the $\mathrm{TEI}_{\mathrm{E}}$ data of Table 1, both time-constants $\mathrm{T}_{1}$ and $\mathrm{T}_{2}$ decrease as the rotation speed goes up, the larger $\Omega_{0}$ and the associated steady current, the faster the surface recovery from abrasion. This can be explained by the huge non-linear character of the perturbation forced in the interface by switching off the pin rotation in contrast to $\mathrm{TEI}_{\mathrm{E}}$. Again the smallest surface charge is associated to the short time-constant whilst the slowest relaxation implies a surface charge of roughly one order of magnitude larger. It can be reasonably supposed that these two time-constants correspond to the formation of a 2-D layer (short times and small charge) followed by the growth of a 3-D layer (longer times and larger charge). Even though the charges, given in Table 2, are more compatible with a film, a few monolayers thick, than those of Table 1, galvanic coupling are also likely to contribute to the anodic charge balance of the surface healing. 


\section{Conclusion}

A new contribution to the understanding of the electrochemistry driven on a passive material under tribological conditions is proposed. An original impedance function, ratio of a mechanical and an electrochemical quantity, is defined and measured. It provides the form of the repassivation kinetics attached to a given steady-state of friction, information generally considered as not accessible to the direct experiment. A two-time-constant response was evidenced, corroborated by additional analysis of the current decay on switching-off the abrasion. These results are discussed in the framework of surface recovery and associated charge balance.

\section{Bibliography}

1. M. Keddam, F. Wenger, 'Electrochemical methods in tribocorrosion. From principles to applications', in Tribocorrosion of passive metals and coatings, D. Landolt et S. Mischler Eds., Woodhead Publishing, UK, (2011), 187-221

2. P. Ponthiaux, F.Wenger, D. Drees, J-P Celis, Electrochemical techniques for studying tribocorrosion processes, Wear, 256, (2004) , 459-468

3. P.Jemmely, S.Mischler, D. Landolt, Electrochemical modeling of passivation phenomena in Tribocorrosion, Wear, 237, (2000), 63-76

4. E.M.Lazarova, Dependence of zero-charge potential for iron, cobalt and nickel on the $\mathrm{pH}$ of a solution., Elektrokhiya, 1978, Soviet Electrochemistry, 1978 , 14, (1978), 1300-1302

5. G.J.Clark, T.N.Andersen, R.S. Valentine, H. Eyring, A comparison of the immersion and open-circuit scrape methods for determining the potential 
of zero-charge of metal electrodes, J. Electrochem. Soc. 121, (1974), $618-622$

6. T.N.Andersen, J.L.Anderson, H. Eyring, The nature of fresh metal surfaces in aqueous solutions, J. Phys. Chem.,73, (1969), 3562-3570

7. S.Mischler, S.Debaud, D.Landolt, Wear-accelerated corrosion of passive metals in tribocorrosion systems, J. Electrochem. Soc., 145, (1998), 750758

8. M.E.Orazem, B. Tribollet., Electrochemical Impedance Spectroscopy, John Wiley \& Sons, page 269, (2011)

9. I.García , D.Drees, J-P Celis, Corrosion-wear of passivating materials in sliding contacts based on a concept of active wear track area, Wear, 249, (2001), 452-460

10. S.Mischler, Triboelectrochemical techniques and interpretation methods in tribocorrosion: A comparative evaluation, Tribology International, 41, $(2008), 573-583$

11. L. Benea, P. Ponthiaux, F. Wenger, J. Galland, D. Hertz, J. Y. Malo, Tribocorrosion of stellite 6 in sulphuric acid medium : electrochemical behaviour and wear, Wear, 256, (2004), 948-953

12. R. Oltra, Depassivation and repassivation phenomena:synergism in tribocorrosion, Chapter 2 in 'Testing Tribocorrosion of passivating materials supporting research and industrial innovation', Handbook, J.-P. Celis \& P. Ponthiaux Ed. European Federation of Corrosion, Maney Publishing. The Institute of Materials, Minerals \& Mining, (2012) 


\section{Acknowledgement}

The authors thank François Wenger for his decisive contribution to the experiments and to fruitful discussions. 


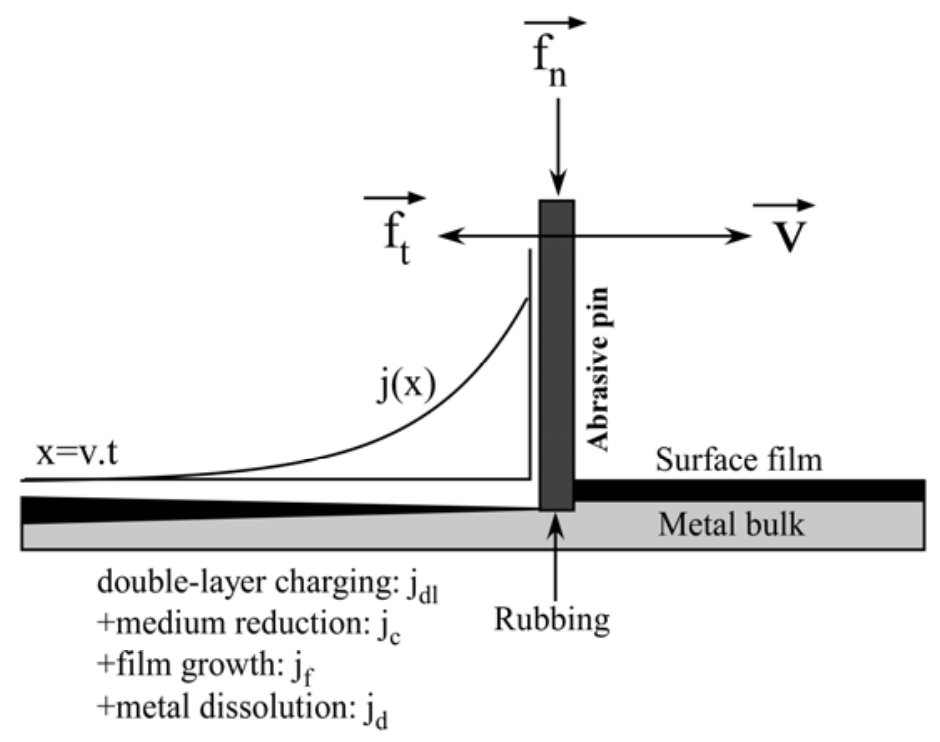

Fig 1: Time-space representation of the surface rubbing by an abrasive body and of the component of the transient current density behind it.

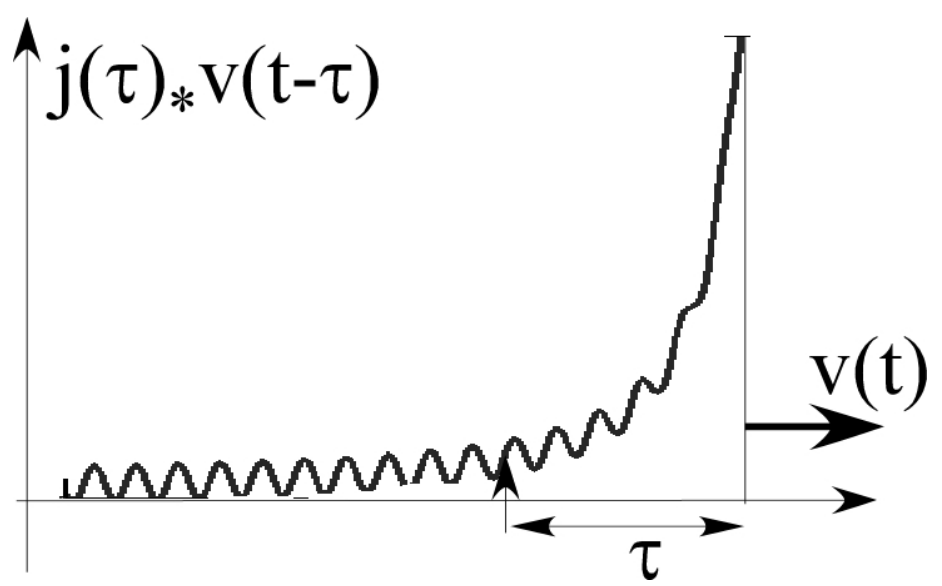

Fig 2 : time profile of the current density $j(t)$ weighted by the velocity of the pin at time $(t-\tau)$ as it contributes to the overall current flowing at time $t$. Case of a sine wave modulation of $\mathrm{v}(\mathrm{t})$. 


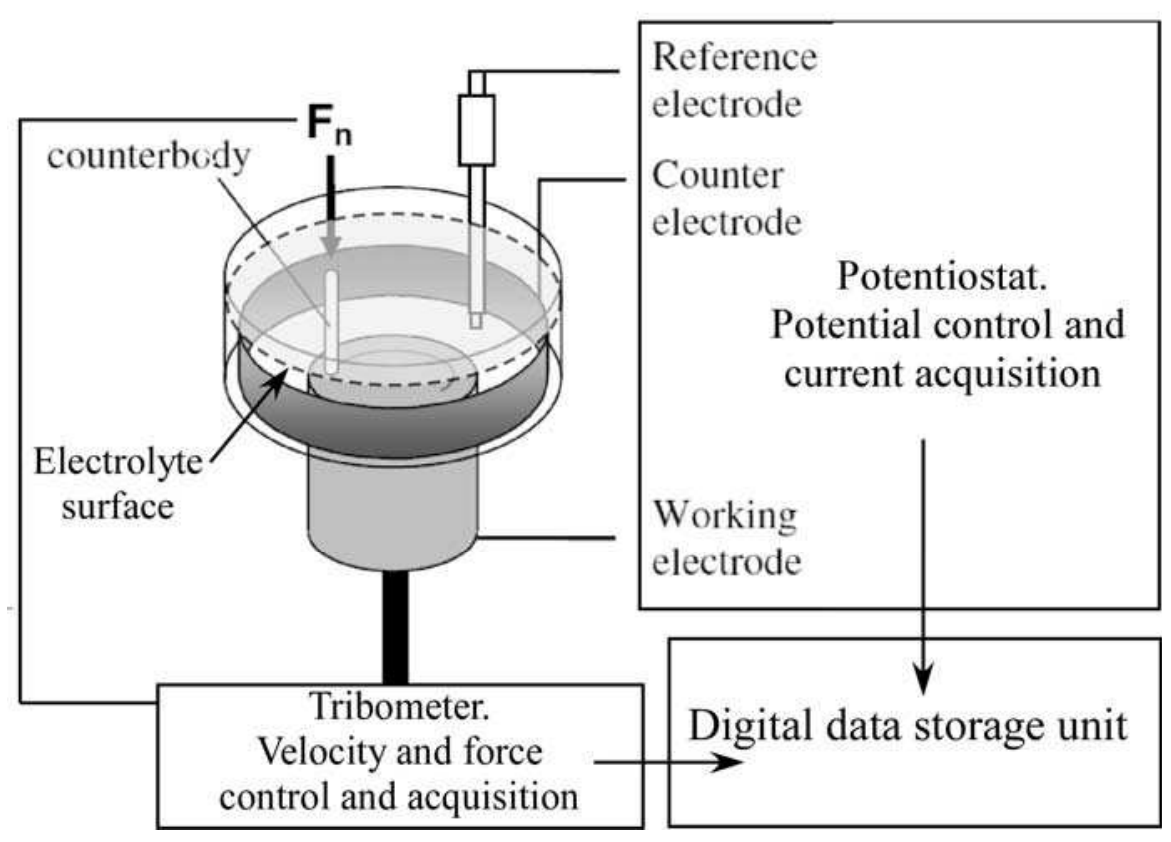

Fig 3: experimental setup for simultaneous measurement and data acquisition of the tribological and electrochemical quantities in a Pin-On-Disc configuration.

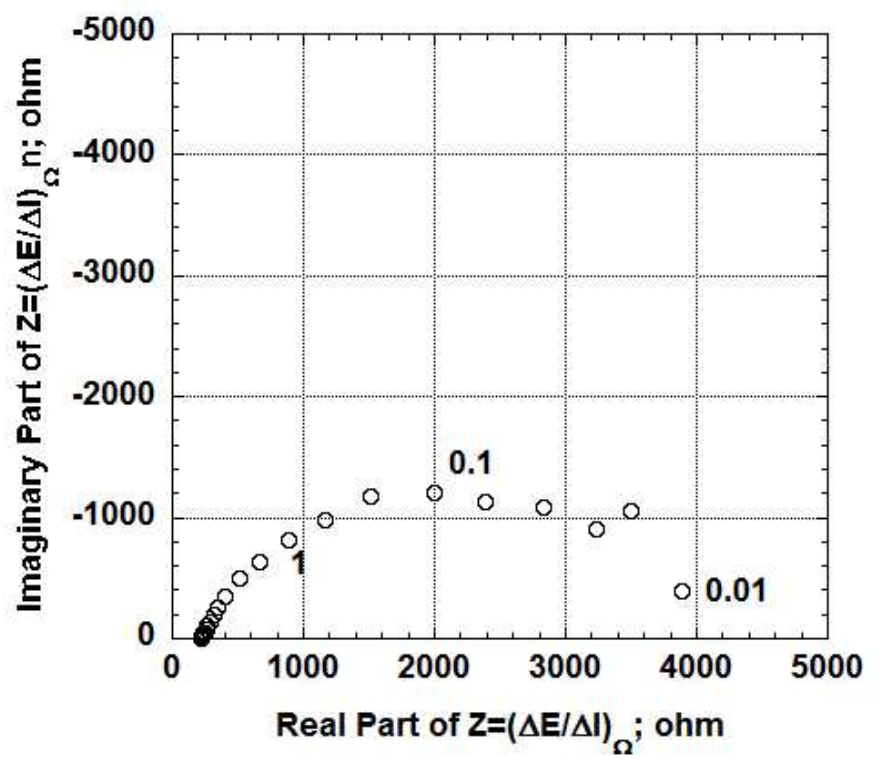

Fig 4: Electrochemical Impedance of AISI 316 in $\mathrm{H}_{3} \mathrm{BO}_{3}(1000$ ppm in $\mathrm{B})+\mathrm{LiOH}(130 \mathrm{ppm}$ in $\mathrm{Li})$ under abrasion at OCP (0,348 Volt $/ \mathrm{Ag}-\mathrm{AgCl} / \mathrm{KCl}$ saturated), rotation speed $\Omega_{\mathrm{o}}=50 \mathrm{RPM}$, relative modulation amplitude $\Delta \Omega / \Omega_{\mathrm{o}}=0.1, \mathrm{f}_{\mathrm{n}}=10 \mathrm{~N}$. 


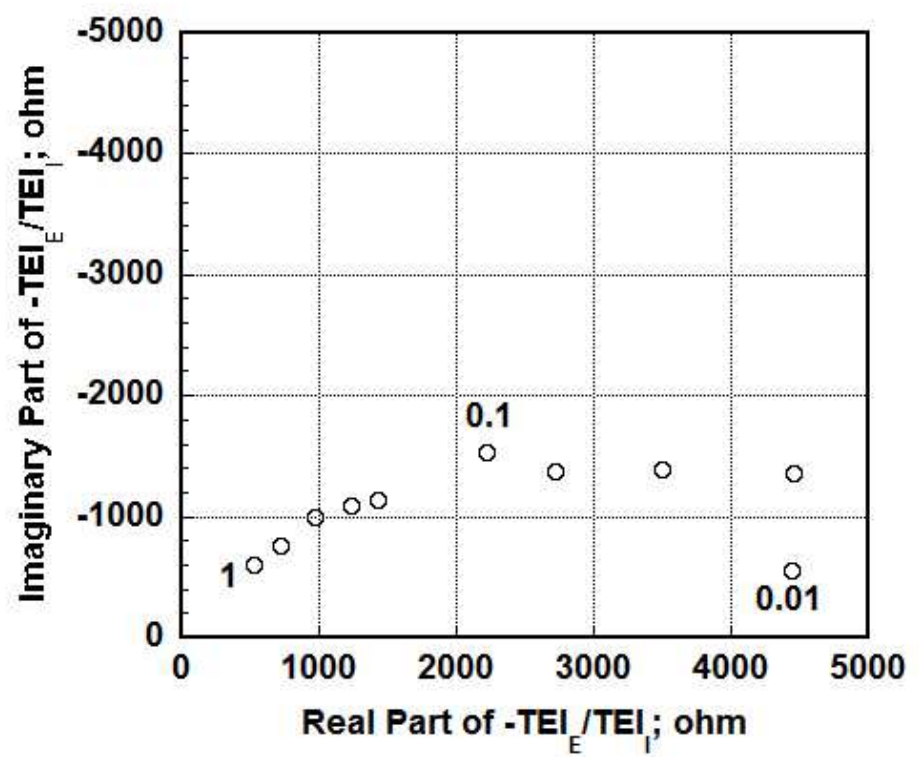

Fig 5: Electrochemical Impedance calculated with $\mathrm{Eq}(8)$ from $\mathrm{TEI}_{\mathrm{I}}$ and $\mathrm{TEI}_{\mathrm{E}}$ measured in the conditions of Fig 4.

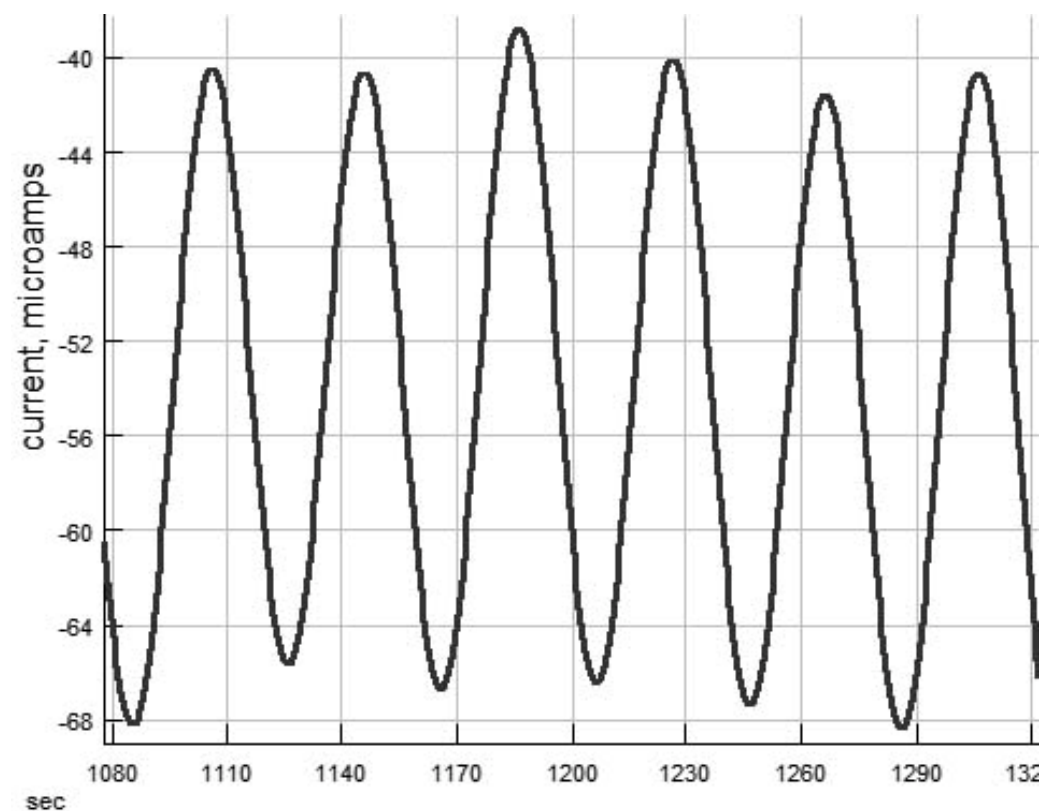

Fig 6 : sample of the current response to the ac modulation of $\Omega$.

AISI 316 L S.S.in boric acid (1000 ppm of boron) and lithia (12 ppm of lithium). Passive range. $+0.1 \mathrm{~V} / \mathrm{Ag} / \mathrm{AgCl} / \mathrm{KCl}$ saturated).

$\Omega \mathrm{o}=50$ RPM. Modulation frequency: $\mathrm{f}=\omega / 2 \pi=0.025 \mathrm{~Hz}$, relative 
modulation amplitude $\Delta \Omega / \Omega_{\mathrm{o}}=0.3, \mathrm{f}_{\mathrm{n}}=5 \mathrm{~N}$. The sign of the current is inversed by the acquisition device.

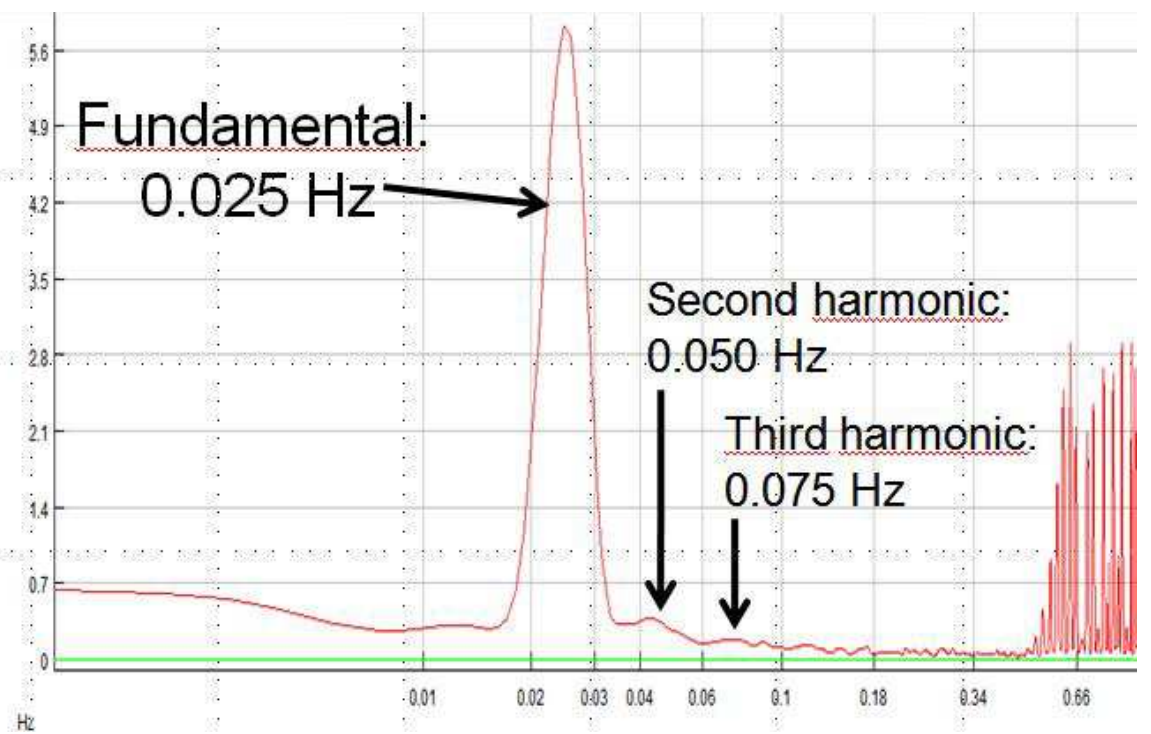

Fig 7: linear-log scale frequency spectrum of the current sample shown in Fig 5.

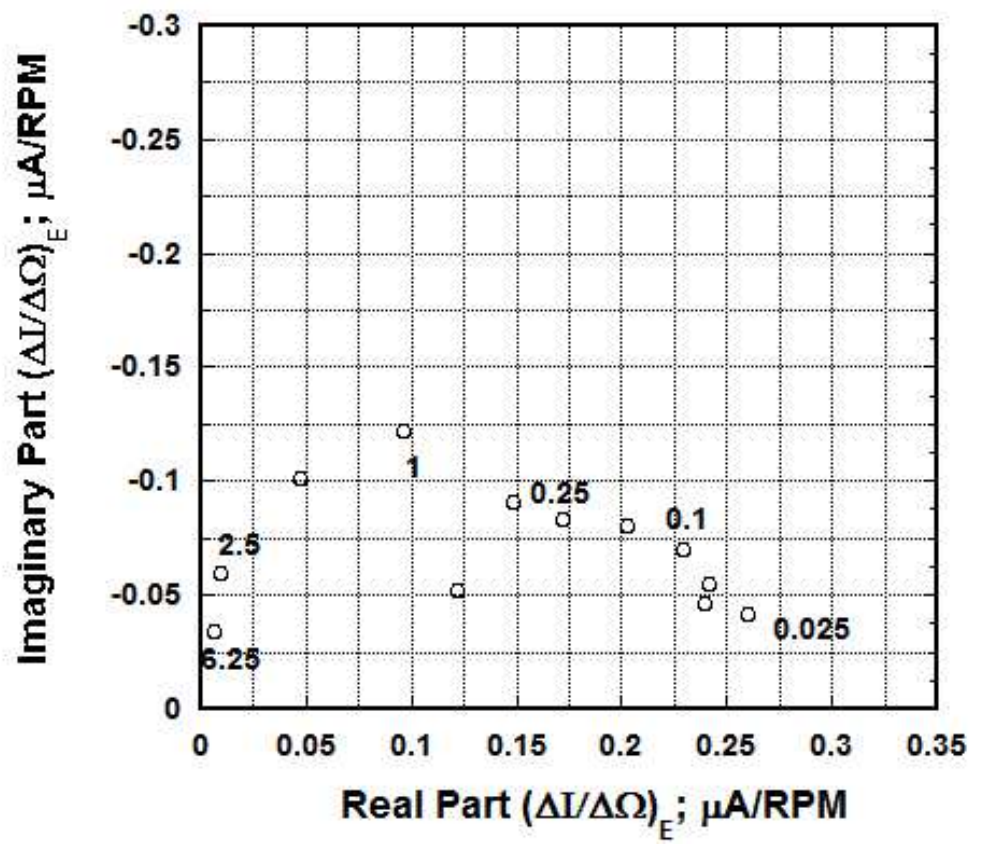


Fig 8: Nyquist plot of the TEI $\mathrm{E}_{\mathrm{E}}$. same conditions as for Fig 6.

$\Omega_{0}=20$ RPM
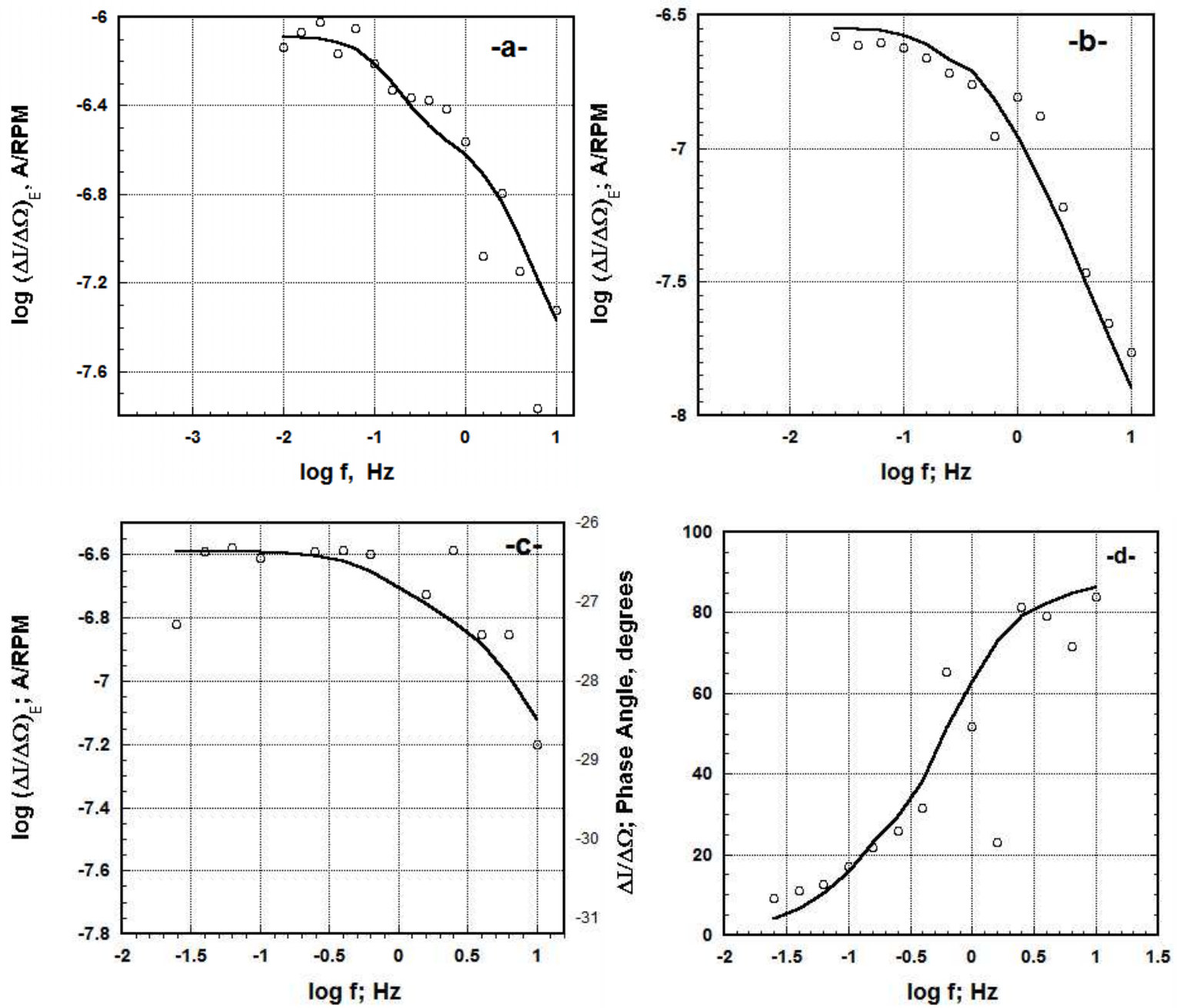

Fig 9: Bode modulus plots of $T E I_{E}$ at three rotation speeds $\Omega_{0}$ : "a", 8RPM, "b", 20RPM, and "c", 50RPM. Same conditions as for Fig 6. "d" : Bode phase plot associated to "b". Solid lines: simulation from $\mathrm{Eq}(8)$. 


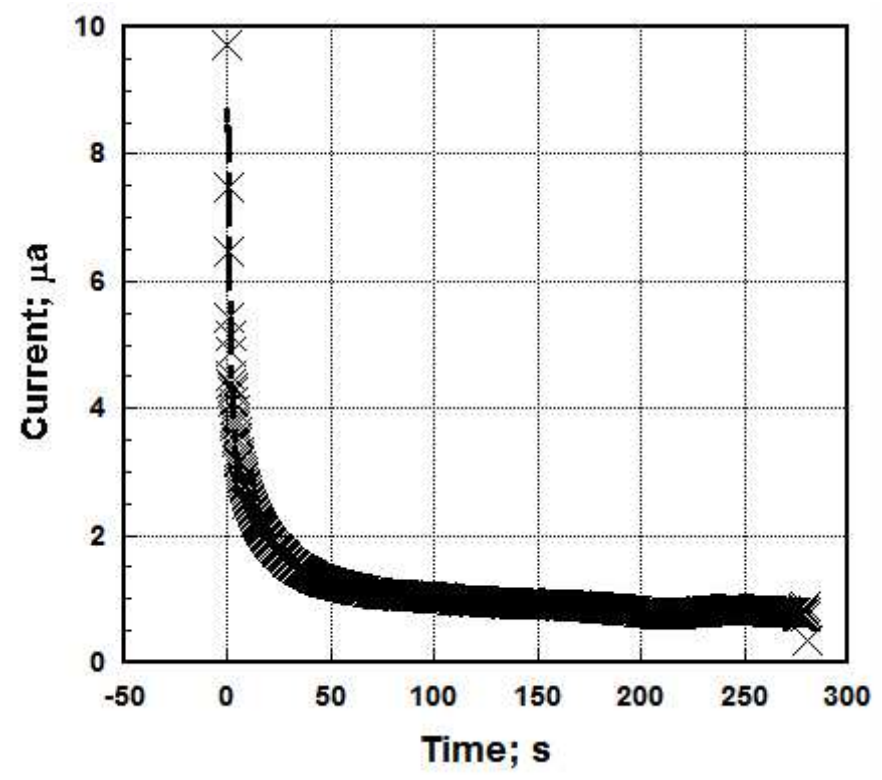

Fig 10: current transient at the end of the rubbing sequence of $\mathrm{TEI}_{\mathrm{E}}$ measurement. Same conditions as for Fig 9 b. Crosses: experiments, solid line: Least Square fit to a two-exponentials decay, correlation coefficient $\mathrm{R}=0.991$. 